\section{Práticas de saúde das equipes dos Consultórios de Rua}

\author{
Health practices by teams from Street Outreach \\ Offices
}

\author{
Prácticas de salud de los equipos de atención \\ callejera
}

\author{
1 Departamento de Pós- \\ graduação em Enfermagem \\ Universidade Federal de \\ Pernambuco, Recife, Brasil. \\ Correspondência \\ F. P. Silva \\ Departamento de Pós \\ graduação em Enfermagem, \\ Universidade Federal de \\ Pernambuco. \\ Av. Prof. Moraes Rego s/n, 2 o \\ piso, bloco A, Recife, $P E$ \\ 50670-901, Brasil. \\ cialle@hotmail.com
}

\begin{abstract}
Two distinctly serious public health problems interconnect in the universe of this study: living on the streets and drug use. To deal with this problem, Street Outreach Offices were created with a prime focus on the life world of drug users living on the streets. The aim was to learn about the health practices used by teams from Street Outreach Offices, in addition to describing their work strategies, learning about the health education provided by the teams, and unveiling their feelings about the work process on the streets. This was a qualitative study with participant observation and content analysis as proposed by Bardin. Analysis of interviews with 15 participants revealed five thematic categories. Health practices by the teams prioritized outreach to (and embracement of) people living on the streets, reinforcing the importance of users participation and interdisciplinary, inter-sector work.
\end{abstract}

Homeless Persons; Drug Users; Health Education; Mental Health
Felicialle Pereira da Silva 1

Iracema da Silva Frazão 1

Francisca Márcia Pereira Linhares 1

\section{Resumo}

Existem dois fenômenos distintos que se interligam, considerados graves problemas de saúde pública: o viver nas ruas e o uso de drogas. Diante dessa problemática os Consultórios de Rua foram implementados privilegiando a abordagem nos contextos de vida do usuário morador de rua. O objetivo foi conhecer as práticas de saúde realizadas no cotidiano das equipes dos Consultórios de Rua, além de descrever as estratégias de atuação das equipes, conhecer o entendimento das equipes sobre educação em saúde e desvelar os sentimentos sobre o processo de trabalho na rua. Trata-se de uma pesquisa qualitativa, com observação participante e análise de conteúdo proposta por Bardin. Da análise das entrevistas de 15 participantes, emergiram cinco categorias temáticas. As práticas de saúde pelas equipes privilegiam o vínculo e o acolhimento das pessoas em situação de rua, reforçando a importância do protagonismo do usuário e da interdisciplinaridade, bem como o trabalho em rede intersetorial.

Sem-Teto; Usuários de Drogas; Educação em Saúde; Saúde Mental 


\section{Introdução}

Existe um número crescente de pessoas da população geral que estão excluídas das estruturas convencionais da sociedade, tendo como resultado o comprometimento de sua saúde, tanto física como psíquica, e consequentemente da sua sobrevivência. É no cenário das ruas onde muitas dessas pessoas buscam "acolhimento", ao mesmo tempo em que se deparam com situações e comportamentos de riscos, entre estes o uso de drogas. O aumento do consumo de drogas, por sua vez, constitui um grave problema de saúde pública em todo o mundo, sendo alvo de planejamento de várias estratégias para minimizá-lo 1,2 .

Assim, este artigo aborda dois fenômenos distintos que se interligam: o uso de drogas e o viver nas ruas. Historicamente não são fenômenos recentes e estão associados a causas multifatoriais que acompanham a humanidade ao longo do tempo ${ }^{3}$. Desde a antiguidade grupos de pessoas já habitavam os espaços da rua em estado de mendicância, entretanto, a distribuição desigual de bens sociais acentuada pelo capitalismo tem culminado em grave exclusão social 4 .

O uso de substâncias psicoativas pela humanidade remonta a um comportamento milenar com o aprendizado das pessoas sobre a utilização de plantas, substratos de origem vegetal e animal para produzir alterações no estado de consciência 5 .

A partir do Século XX, ese contexto sofreu mudanças com a regulamentação do uso dessas substâncias, tendo sido classificadas em lícitas e ilícitas 6 . Esse status de ilegalidade parece ter contribuído para o crescimento da oferta e valorização dessas drogas, ampliando o seu consumo 7 .

No Brasil, a transformação do uso de drogas num problema público ocorreu nas últimas décadas do Século XIX, instituindo novas práticas de controle social. No final da década de 70 , esse cenário passou por outro processo de mudanças, especialmente voltado para o consumo de drogas ilícitas que passaram a ser relacionadas à pobreza, violência, abandono, insucessos pessoais e falência financeira 8 .

Apesar das substâncias psicoativas serem utilizadas por pessoas de diferentes classes sociais, a associação entre marginalidade e "ser" de rua é bastante difundida na sociedade. Verifica-se que o uso de múltiplas drogas é uma prática regular nessa população, porém não se pode afirmar se esses hábitos são prévios, adquiridos nas ruas, ou até mesmo determinantes para ida às ruas ${ }^{9}$.

Torna-se relevante destacar que as políticas públicas de saúde historicamente permitiram a existência de uma lacuna assistencial, uma vez que a questão das drogas era referenciada para instituições de justiça, segurança pública e associações religiosas. Assim, sendo o indivíduo considerado doente e incapaz de responder por suas escolhas, os modelos de tratamento tradicionais convergiam para o uso imperativo da abstinência 10 .

Em reconhecimento a essa problemática, o Programa Nacional de Atenção Integral aos Usuários de Álcool e outras Drogas, implementado pelo Ministério da Saúde, tem como proposta a ampliação do acesso ao tratamento e a promoção do direito de cidadania com abordagem na redução de danos 11,12. A redução de danos é uma estratégia que constitui um conjunto de medidas em saúde com o objetivo de minimizar as consequências adversas provenientes do uso e abuso de substâncias psicoativas, tendo como princípio fundamental o respeito à liberdade de escolha do indivíduo e o acesso aos serviços de saúde 13 .

Tais pautas contribuíram para o surgimento dos Consultórios de Rua, com base em uma experiência idealizada e proposta pelo Dr. Antônio Nery Filho, na cidade de Salvador, Estado da Bahia, Brasil, com ofertas de serviços na modalidade de atendimento extramuros, objetivando promover acessibilidade aos serviços de saúde, assistência integral aos usuários de rua e promoção de laços sociais com enfoque intersetorial. A avaliação dessa experiência realizada entre 1999 e 2006 foi considerada exitosa, permitindo a inclusão do Consultório de Rua no Plano Emergencial de Ampliação de Acesso ao Tratamento e Prevenção em Álcool e outras Drogas (PEAD), e em 2010, no Plano Integrado de Enfrentamento ao Crack 14.

A experiência de Salvador passou a ser referência para novos projetos do Ministério da Saúde, contribuindo na ampliação do acesso aos serviços e fortalecimento da rede de atenção à saúde. Assim, sob a Portaria no 122 15, de 25 de janeiro de 2012, surgem os Consultórios de Rua, transferindo para a atenção básica o atendimento à população em situação de rua a partir da atuação de suas equipes 15 . Nesse sentido, na busca de uma assistência integral para as pessoas em situação de rua, entende-se que as ações educativas dirigidas a essa população são estratégias essenciais para a prática das equipes, e, portanto, devem ser pautadas em ação/reflexão/ação, como processo de leitura da realidade, dialogicidade e conscientização 16 .

Este trabalho tem como objetivo conhecer as práticas de saúde desenvolvidas pelas equipes do Consultório de Rua. As práticas de saúde dentro desse cenário são aquelas que incorporam o cotidiano do trabalho em saúde, e neste 
contexto, contemplam os desdobramentos de uma metodologia direcionada para o cuidado integral da população de rua pelas equipes (Peduzzi M, Schraiber LB. Dicionário de Educação Profissional em Saúde. http://www.epsjv.fiocruz. br/dicionario/, acessado em 12/Dez/2012). Estudos acerca da temática do Consultório de Rua são escassos, os materiais encontrados estão direcionados na maioria para a capacitação dos profissionais. Foram utilizados na discussão os constructos da autonomia e conscientização de Paulo Freire, uma vez que estes constructos configuram uma atividade essencial e reflexiva da prática educativa 17 .

\section{Percurso metodológico}

Trata-se de um estudo exploratório, descritivo, inserido nos pressupostos da análise qualitativa. Optou-se por essa abordagem uma vez que trabalha "com universo de significados, motivos, aspirações, crenças, valores e atitudes” 18 (p. 28).

A pesquisa foi realizada no Estado de Pernambuco, nos municípios de Recife e Olinda, contemplados com os Consultórios de Rua desde 2010, com equipes de diferentes configurações, rotinas e organização.

Participou do estudo uma equipe de cada município, totalizando 15 trabalhadores de saúde. Desses, seis são de Recife e nove de Olinda. Essas equipes desenvolvem um trabalho de formação de vínculo com a população de rua. Quanto à caracterização profissional, a primeira equipe foi composta por um assistente social, um oficineiro de capoeira e quatro redutores de danos. A segunda foi formada por um enfermeiro, um assistente social, um psicólogo e seis redutores de danos. Os redutores de danos são agentes de saúde, geralmente escolhidos entre as pessoas da comunidade, que possuem compromisso quanto à promoção da saúde e cidadania de usuários de drogas 19.

A pesquisa foi realizada na base operacional dos trabalhadores e na rua, uma vez que são nestes cenários que os profissionais atuam.

A coleta de dados foi realizada durante os meses de junho e julho de 2012 por meio da técnica de entrevista semi-estruturada e da observação participante, registrada em diário de campo. Buscou-se dessa forma a utilização da triangulação de métodos para reforçar a credibilidade do estudo 20 . A observação participante foi realizada in loco pela pesquisadora responsável, nos períodos diurno e noturno, durante os trinta dias de coleta para cada município, contemplando diversos cenários, acompanhando as abordagens das equipes junto aos usuários de rua. Foi utili- zado um roteiro previamente elaborado contendo dinâmicas de funcionamento, abordagens e estratégias utilizadas pelas equipes.

As entrevistas foram realizadas individualmente na base operacional dos trabalhadores, em horários combinados e com duração aproximada de quarenta minutos. Foram conduzidas pelas seguintes questões norteadoras: “Como são as atividades que você desenvolve em sua prática nos Consultórios de Rua?”, "O que você entende sobre educação em saúde?”, “Como você se sente realizando este trabalho?" As falas foram gravadas em aparelho de voz digital e transcritas na íntegra em grelhas de análise. Ao final da transcrição foi realizada uma leitura exaustiva. Os dados foram examinados segundo a análise de conteúdo de modalidade temática proposta por Bardin 21

A análise dos dados permitiu a identificação de núcleos de sentido, após os recortes, dos trechos das falas, nos quais foi realizada a categorização pelo sentido expressado. Esses dados foram discutidos em acordo com os constructos teóricos de autonomia e conscientização propostos por Paulo Freire 22,23.

Após a identificação dos resultados da análise temática, realizou-se a verificação com os participantes no sentido de oportunizar questionamentos, bem como fornecer feedback aos mesmos quanto às interpretações preliminares. Essa técnica de verificação é considerada importante para o estabelecimento de credibilidade dos dados qualitativos 20 .

O trabalho atendeu aos preceitos éticos da Resolução no 196/96 do Conselho Nacional de Saúde, que rege as pesquisas com seres humanos, aprovada com o número do CAAE 01184312.5.0000.5208.

\section{Resultados}

\section{Caracterização dos participantes}

Participaram do estudo 15 profissionais de saúde, sendo oito do sexo masculino e sete do feminino, distribuídos nas duas equipes, compostas na totalidade por: uma enfermeira, uma psicóloga, dois assistentes sociais e 11 redutores de danos. Esses últimos têm formação por meio de capacitações promovidas pelas secretarias de saúde.

A faixa etária dos entrevistados variou entre 24 e 50 anos, sendo a idade média de 30 anos. Quanto ao tempo de experiência profissional, a maioria (oito) está entre 1 e 2 anos, enquanto que na área de saúde mental apenas dois referiram ter esta especialidade e experiência anterior na 
área. Com relação à forma de ingresso, nove foram por indicação de outros colegas, tendo vínculo por contrato, e seis por processo seletivo de concurso público.

Da análise de conteúdo emergiram cinco categorias temáticas: (1) atividades em equipe nos consultórios de rua; (2) valorização da construção do vínculo; (3) educação em saúde como estratégia na redução de danos; (4) satisfação com a proposta de cuidado do Consultório de Rua; (5) desafio proposto na atuação do Consultório de Rua.

Tema I: atividades em equipe nos Consultórios de Rua

As equipes dos Consultórios de Rua, distribuídas nos municípios pesquisados, não constituem uma configuração homogênea do ponto de vista numérico e multidisciplinar, sendo uma equipe contemplada por um assistente social e quatro redutores de danos, e a outra por uma enfermeira, uma assistente social, uma psicóloga e seis redutores de danos.

Para a realização das atividades no Consultório de Rua, as equipes dispõem de transporte automotivo que referenciam a equipe na área $\mathrm{e}$ serve tanto para o deslocamento dos profissionais e usuários como para levar insumos.

“...Aí nos trabalhamos com a van, um carro, esse carro serve tanto para o deslocamento dos profissionais quanto para levar materiais, insumos, quanto para o transporte dos usuários e principalmente para estar referenciando a equipe lá na área..." (E9).

A atuação das equipes do Consultório de Rua é precedida de reuniões de pré-campo que tem como objetivo o planejamento das atividades e discussão de estratégias. Também é realizada a reunião do pós-campo para avaliar as atividades executadas. Os profissionais dizem em suas falas que as abordagens aos usuários de rua são in loco, tendo o território como referência. Durante as atividades desenvolvidas, são inclusos tanto os moradores de rua, como pessoas em situação de rua.

“...A gente atua fazendo intervenção nos locais onde eles [moradores de rua] estão, seja ponto de uso, seja residência... né?" (E1).

“...Lá mesmo... na rua mesmo e fazendo o monitoramento deles no dia da área” (E2).

Para o desenvolvimento das atividades na rua, os territórios são previamente estudados e mapeados pelas equipes, a fim de selecionar as prioridades de atenção de acordo com o índice maior de violência e de pessoas em situação de rua e/ou que fazem uso abusivo de álcool e outras drogas. Esse mapeamento é também arti- culado com as lideranças comunitárias e com os agentes da rede básica de saúde.

Com o objetivo de contemplar as necessidades do território, as ações noturnas são estratégias que objetivam alcançar usuários que as equipes não conseguem acessar no período diurno. Uma das equipes analisadas refere que desenvolve duas formas de funcionamento: durante o dia a equipe atua separadamente nos distritos de saúde, e à noite em grupos, como pode ser observado nas falas dos E12 e E15, respectivamente:

“...Essa instituição [Consultório de Rua] tem duas configurações: a equipe do dia e a da noite, que trabalha mais com a situação de rua" (E12).

“...Já à noite a gente trabalha mais a lógica de grupo, o grupo todo para o território” (E15).

Os cenários de atuação variam conforme o território. Em geral observa-se que os usuários se "amontoam" pelas calçadas e praças para partilhar um universo particular, com seus poucos pertences dentro de sacos plásticos pelo chão, ou ainda com seus colchões rasgados que são vistos pelas calçadas durante o dia. Privacidade tem um sentido inexistente na rua.

A observação em campo e a produção dos dados por meio da entrevista visualizaram a significância do trabalho em equipe para oferecer um cuidado integral às pessoas em situação de rua. O sentido de pertencimento que emana do fenômeno de grupo é claramente destacado por meio de uma práxis que entende que cada um tem um olhar diferenciado e saberes plurais para vasculhar em diferentes áreas do conhecimento. Na fala que segue, percebe-se que trata-se de uma necessidade consciente na práxis da equipe dos Consultórios de Rua.

“...Somos uma equipe multidisciplinar que tem uma quantidade de olhares diferenciados e saberes plurais para poder estar atendendo de forma integral a essas pessoas: biopsicossocial" (E9).

“...Nós fazemos a inserção deles na rede de saúde prioritariamente e em toda rede intersetorial, na rede de assistência social e outras mais que eles precisarem" (E9).

Nesse sentido, uma situação é exemplificada quanto a situações específicas que emergem nas ruas, como pode ser observado nas falas do E1 e E3:

"Se ele [morador de rua] traz uma demanda de saúde, faço uma interlocução com a enfermeira para que ela tenha um olhar e tal... e trabalho com ele a redução de danos" (E1).

“...E ele [morador de rua] tiver com alguma ferida, alguma danificação corporal... a gente vai tá ali contando com a enfermeira e ela vai estar ajustando isso, trabalhando em cima disso" (E3). 
A multidisciplinaridade mais uma vez é ressaltada pela equipe, reforçando que cada profissional deve ter seu papel delimitado dentro da sua área do conhecimento. A fala de um dos entrevistados revelou que a área de saúde mental necessita de reflexão acerca da compreensão das especificidades, não generalizando o que cada um pode fazer, respeitando o potencial do trabalho interdisciplinar. Essa dificuldade emerge como muita força, pois a equipe entende que a abordagem ampliada permite apreensão conjunta, sendo essencialmente necessária para ações integrais às pessoas de rua.

“...A área de saúde mental ainda é um campo de trabalho com uma lógica psicologizante, não entende que as profissões não estão ali para se digladiar, pelo contrário, estão ali para se complementarem e oferecer um serviço de qualidade para o usuário" (E13).

Ainda nessa fala, esse entrevistado considerou que o profissional deve refletir sobre o seu papel e firmar o seu espaço dentro do compromisso da construção de um cuidado ético.

\section{Tema II: valorização da construção do vínculo}

Para o desenvolvimento do trabalho nos Consultórios de Rua, os entrevistados consideram imprescindível a construção do vínculo com os usuários de rua. Essa tarefa, no entanto, requer da equipe o exercício de uma práxis que envolve criatividade e subjetividade como construções humanas significativas para este trabalho diferenciado, bem destacado na fala do E1:

"É você ter um olhar técnico-humano né... é um trabalho diferenciado" (E1).

“...Geralmente os redutores de danos, eles são pessoas que se adaptam aos usuários, por conta até do visual também e a linguagem. A gente chega normalmente e dá um bom dia, começa a conversar que eles se sentem bem..." (E3).

No exercício dessa construção do vínculo com a população de rua, a relação dialógica e o saber escutar constituem saberes necessários. A equipe exerce a prática de acordo com a necessidade do campo, utilizando-se de oficinas de arte em geral como a música, pinturas, desenhos, capoeira, instrumentos de percussão, entre outros. Nesse sentido, as equipes reconhecem que essas atividades realizadas na rua permitem que os usuários sintam-se mais à vontade para a participação e construção do vínculo.

"Aí assim, a gente trabalha muito com a música, com a arte em geral, questão de desenho, de pintura, leva a atividade para o campo, para que eles se sintam à vontade lá na área deles, em casa, porque na verdade a casa deles é a rua mesmo..." (E8).
Essa solidariedade e sensibilidade tão presentes neste trabalho são traduzidas quando a maioria dos entrevistados refere que não há resistência por parte dos usuários, que estes não oferecem obstáculos para serem cuidados.

“...Às vezes existem brigas e conflitos dentro de casa, e daí você poder mostrar os caminhos, $e$ você vai perceber que as pessoas lhe escutam eque estão ali e acabam querendo ser cuidado, é massa isso, muito satisfatório mesmo!" (E1).

As ações de saúde realizadas no cotidiano de trabalho das equipes buscam identificar as demandas dos usuários de rua numa abordagem integral articulada à rede básica de saúde e à rede intersetorial. O usuário de rua geralmente encontra-se com vínculos familiares rompidos ou fragilizados, desta forma, a tentativa das equipes em resgatar estes vínculos é bastante vivenciada nesta prática.

“...E aí a gente articula os serviços e não só os serviços da rede de saúde, da rede psicossocial, mas também outros atores da comunidade" (E14).

Para esse trabalho tão complexo, existe a necessidade de incluir outros atores no território por meio de parcerias para atuação em conjunto. Algumas ações como oficinas regulares de capoeira são realizadas estrategicamente como atividade cultural em um dos municípios pesquisados e acontecem nos Centros de Atenção Psicossocial Álcool e outras Drogas (CAPSad).

Tema III: educação em saúde como estratégia na redução de danos

As equipes reconhecem que as pessoas que estão em situação de rua não dispõem de saúde, de acesso à educação e dos direitos de cidadania, portanto se propõem a ser um elo entre a rua e a saúde. Essa premissa entra como estratégia central das equipes do Consultório de Rua, tanto para entrada no campo como no desenvolvimento da prática.

“...A gente é um elo entre a saúde e a rua, eles como são moradores de rua, não dispõem de saúde, de documentação, dessas coisas... e a gente procura dizer que quer levar isso para ele [morador de rua], a saúde" (E4).

“...Na verdade a gente funciona como uma ponte para eles terem acesso à rede de saúde básica... a gente tenta fazer essa ponte e serve como link dessa população e a atenção básica" (E5).

A educação em saúde está inserida em todas as etapas da proposta de trabalho da equipe, considerando que esta desenvolve um cuidado diário que depende da identificação das necessidades dos moradores de rua. Esse cuidado, porém, é estabelecido com base em uma relação de respeito, que entende a educação em saúde 
como uma ferramenta para proporcionar o exercício de cidadania dos moradores de rua, bem destacada nas falas a seguir: “...educação em saúde para mim é levar o sujeito a refletir sobre suas escolhas, suas demandas né... e exercer e potencializar o exercício de cidadania desses usuários" (E12).

"Educação em saúde seria a gente trabalhar a qualidade de vida desse sujeito... eu vou falar da clínica ampliada, ou seja, com uma visão mais ampla, quando a gente vai fazer a abordagem, eu não vou focar apenas a droga desse sujeito, mas também outras questões além do uso da droga" (E15).

A redução de danos no entendimento da equipe não é exclusiva dos usuários de substâncias psicoativas e, portanto, considerada tanto como porta de entrada quanto como proposta de metas e estratégias para a construção do projeto terapêutico do usuário de rua.

“...Educação em saúde eu vejo... voltado para o tipo de trabalho que a gente faz, eu acho que ela traz muito a questão da redução de danos... a gente faz com essa população [de rua], seja ela usuária de drogas ou não" (E4).

“...Fazer educação em saúde no meu entender é você viver bem... redução de danos também é tudo isso aí, se você consegue usar aquela droga de forma menos danosa, você vai ter mais saúde... você vai ser uma pessoa melhor" (E6).

“...Ele é corresponsável pelo cuidado de si... uma das coisas que me chama a atenção na redução de danos é que esse sujeito se autorregula..." (E12).

Tema IV: satisfação com a proposta de cuidado do Consultório de Rua

Existe uma gratificação pessoal em desenvolver um trabalho direcionado aos moradores de rua. Essa atenção, no entanto, está desvinculada de um olhar puramente assistencialista, considerando as pessoas em situação de rua como os seres humanos que de fato são.

“...Além do respeito que você ganha das pessoas, tem que eu acabei melhorando muito como ser humano. Confesso que antes de trabalhar com moradores de rua não existia uma visão para um morador de rua, mais pena do que uma visão de um cara que precisa de ajuda..." (E1).

"Mas o importante de tudo é você fazer contato com pessoas né... é você estabelecer linhas de cuidado com pessoas, com pessoas diferentes, com singularidades e particularidades, individuais e únicas" (E10).

Esse reconhecimento do trabalho da equipe está bem detalhado no relato do entrevistado E1 num diálogo entre ele e um morador de rua:
“Eu gosto de vocês porque vocês veem a gente como gente. Mas vocês são gente. Eu sei que sou gente, mas as pessoas pensam que eu não sou gente" (E1).

As pessoas em situação de rua parecem reconhecer a si mesmos como oprimidos e imersos em uma realidade da qual muitas vezes não conseguem superar, e uma delas é não se sentirem reconhecidos como pessoas pela sociedade.

A equipe reconhece e vivencia essa realidade, e considera representativa à aplicação dos sentidos humanos em colocar sempre em primeira escala o desejo do usuário, fato este que rejeita a possibilidade deste ser reduzido a um trabalho frustrante, considerando as dificuldades sociais e mesmo internas dessa população de rua.

\section{Tema V: desafios na atuação do Consultório de Rua}

As equipes proferem que existem desafios para o cuidado com as pessoas de rua. Esses desafios constituem barreiras que dificultam, inibem ou até mesmo inviabilizam o acesso do morador de rua à rede de saúde e à rede intersetorial. A barreira social foi citada como uma das principais causas, da qual envolve o estigma e reforça a invisibilidade dessas pessoas, como pode ser observado na fala de E1:

“A barreira mais gritante é a social, infelizmente esta estigmatização que as pessoas têm com usuários de drogas e morador de rua [...]" (E1).

Esse entrevistado refere que o fator social acaba influenciando diretamente os profissionais que as equipes precisam acessar, principalmente os da saúde. Não que a questão seja exclusivamente relacionada à rede de saúde, mas uma questão explicitamente social, como mostra o depoimento a seguir:

“...É uma coisa mais social mesmo, aquelas coisas que são referências que a gente traz e que a gente acaba se tornando profissional e acaba reproduzindo da mesma forma, sabe, a gente tá acostumada a receber aquela pessoa limpinha, organizada, que tem documentos, que tem endereços e tal..." (E1).

Essa expressão reflete o preconceito social que consequentemente atinge os profissionais de saúde e os direciona ao trabalho pautado em diretrizes burocráticas, sendo uma das barreiras que dificultam o acesso das pessoas de rua à rede de saúde. Diante dessa realidade, a equipe reconhece que uma pessoa não deixa de ser um humano por não ter endereço, documentos ou higiene.

A responsabilidade reflexiva de poder fazer o melhor ou buscar o que de melhor pode ser feito para o cuidado dos moradores de rua está 
refletida no sentimento de desafio, como pode ser observado a seguir:

“...Você se depara com um desafio e em relação ao desafio, você tem o receio de não estar fazendo o que deveria ser feito, vamos dizer assim" (E13).

“...Muita gente diz que este tipo de trabalho é muito frustrante, porque você encaminha os usuários, de repente eles passam por um tratamento, daqui a pouco eles voltam, tem uma recaída e aí o pessoal se frustra né? Mas na realidade é como eu digo: o desejo que tem que tá em jogo é o desejo do usuário e não o desejo do profissional..." (E5).

\section{Discussão}

O texto para II Oficina Nacional dos Consultórios de Rua, publicado pelo Ministério da Saúde, refere que a equipe volante mínima do Consultório de Rua deve ser constituída por profissionais da saúde mental, entretanto a Portaria no 122 de 25 de janeiro de 2012 que dispõe sobre as equipes do Consultório de Rua não destaca esta particularidade na sua composição 5,15. Entende-se dessa forma pelos formatos e heterogeneidade das equipes que estão sendo formadas de acordo com deliberações das respectivas gestões municipais, fato este que merece ser repensado.

As abordagens realizadas no campo pelas equipes do Consultório de Rua privilegiam uma estratégia de aproximação desenvolvendo uma oferta de cuidados e redução de agravos fora dos espaços institucionais. Essa lógica de trabalho integra o Consultório de Rua como dispositivo público componente da rede de atenção substitutiva em saúde mental 24. Dando seguimento a essa lógica, os espaços de rua compõem o território como um todo, onde as equipes procuram assegurar o cuidado em redes buscando a integração destas às necessidades do usuário.

Pode-se verificar que as ações de saúde realizadas na prática das equipes dependem prioritariamente das demandas dos usuários, portanto trata-se de ações variadas que precisam envolver vários atores na comunidade como parceiros essenciais para possibilitar ações conjuntas e efetivas. Entre esses atores, estão a assistência social e a rede básica de saúde, bem como outros dispositivos no território. Dessa forma, considera-se que a atuação no próprio contexto de vida e a compreensão da identidade cultural do indivíduo são fundamentais para a prática educativa e para a construção conjunta de seu projeto terapêutico 22 .

Entre as formas de atuação foram citadas as ações em "sindicatos" que as equipes referem como sendo bares e barracas, nas escolas, de capacitação de agentes comunitários da área de abrangência, na articulação com a rede básica e com a própria comunidade. Nesse sentido, a comunidade é uma importante parceira que identifica demandas, colaborando na busca ativa com as equipes do Consultório de Rua. Essas parcerias concluem e reforçam o entendimento de que a saúde é intersetorial, conforme foi afirmado no relatório final da IV Conferência de Saúde Mental. Essa defende o acompanhamento intersetorial integral, levando em conta as especificidades da população de rua, particularmente a de não ter território definido 25,26.

No imaginário das equipes, o cuidado ao indivíduo em situação de rua, além da competência técnica do profissional, depende de suas qualidades humanas, solidariedade e intencionalidade para compreender a pessoa a ser cuidada e para que este cuidado seja prestado de acordo com as suas necessidades.

Essa compreensão inclui não permitir que interferências de preconceitos que rotulam as pessoas como viciado, ladrão, agressivo ou perigoso os impeçam de ver a pessoa, descobrir o que ela sabe, o que traz de bom e no que pode melhorar. Esse pensamento da equipe corrobora o de Paulo Freire na medida em que o compromisso assumido aqui não pode ser um ato passivo, mas práxis, ação e reflexão sobre a realidade, que só é válido quando carregado de humanismo 27.

Como forma de vínculo, identificou-se que o contato prévio da equipe com os parceiros da comunidade é uma importante estratégia para a entrada no território, além de reforçar a referência do trabalho dos Consultórios de Rua. Nesse sentido, Freire enfatiza que a intercomunicação é um processo que mediatizado pela realidade produz autenticidade ao pensar do educador e do educando 11 .

As práticas educativas em saúde, para a equipe, também se referem a um processo efetivo de troca, em que ao se passar um determinado conhecimento específico para a população, a equipe aprende a forma de fazer deste determinado grupo. Portanto, é ressaltada a relevância de transmitir a informação da forma que o grupo possa compreender, entendendo a dinâmica vivenciada pelos sujeitos. De acordo com Freire, esse processo perpassa a mera transmissão de conhecimentos, sendo uma "via de mão dupla", na qual a construção do conhecimento se dá por meio de reflexão crítica sobre a realidade vivenciada 27 . Essa compreensão está inserida nos pressupostos da educação problematizadora, em que ambos, educador (equipe), educando (usuário de rua) se tornam sujeitos de crescimento e aprendizado mútuo ${ }^{17}$.

Os discursos dos entrevistados convergem para a constatação de que as práticas educativas 
realizadas com e para os usuários estão pautadas na política da redução de danos. Foram bastante citadas as formas práticas de abordagem à população de rua, bem como aquelas observadas em campo. No entendimento das equipes, o processo de educar em saúde envolve a necessidade de conhecer e compreender o contexto de cada indivíduo, a partir da realidade e possibilidades de cada um, com base no respeito à sua autonomia e direito do sujeito ativo no seu plano terapêutico.

Nesse sentido, a educação em saúde pode ser concebida como uma prática libertadora, levando o indivíduo a refletir e intervir sobre sua realidade, transformando-a. O trabalho envolvendo a educação em saúde fornece subsídio para desenvolver outra prática, que é mais instigante, e que se refere a lidar com o empoderamento dos sujeitos. A informação leva o indivíduo ao empoderamento pela conscientização, e esta não pode existir fora da práxis, ou seja, sem o ato ação-reflexão-ação 23 .

Apesar dos obstáculos que esse tipo de trabalho enfrenta, o sentimento de gratificação pessoal da equipe foi absolutamente marcante nos discursos, bem como na observação de campo. As equipes referiram ter consciência de estarem contribuindo para "salvar vidas", fazendo com que as pessoas possam viver mais e melhor, dentro de suas possibilidades.

A ação para integralidade nos cuidados de saúde necessita do olhar multiprofissional, para possibilitar apreensão ampliada das necessidades reais de uma população 28,29. Além disso, devido à precariedade e situações adversas a que os indivíduos estão expostos nesses cenários, a presença do profissional enfermeiro na equipe é essencial, considerando que este possui uma valiosa contribuição advinda de uma formação holística com base no cuidar do ser humano, família e comunidade. Dessa forma, torna-se relevante a compreensão de que para oferecer um cuidado compartilhado e integral, a presença desse profissional na equipe deve ser assegurada.

O desafio a que a equipe se refere, reflete um pensamento profundo de Freire de que quanto mais se problematizam os educandos, como seres no mundo e com o mundo, tanto mais se sentirão desafiados e ainda mais: obrigados a responder ao desafio 17 . Outra questão relacionada ao tema está na necessidade de reestruturação dos serviços em articulação com os demais componentes da rede. De acordo com Freire, a conscientização nos capacita para assumirmos o compromisso de sermos anunciadores e denunciadores em busca de transformar uma realidade 17, isto para as equipes do Consultório de Rua exige uma permanente busca, sendo a essência da sua práxis.

\section{Considerações finais}

A prática das equipes dos Consultórios de Rua é observada em coerência nos discursos. A dinâmica desse trabalho permite a compreensão do desafio de conhecer e se apropriar de uma realidade para transformá-la. A realidade aqui referida está submersa no contexto de desigualdade social da população de rua, que além das precárias condições de vida, carregam o fardo pesado da invisibilidade como ser humano.

Não é fácil (re)significar o outro ofertando cuidado, sobretudo quando este outro é usuário de drogas e ou morador de rua. Os desafios explicitados pelas equipes refletem a necessidade da incorporação de um novo paradigma, que envolve o morador de rua ocupando um novo lugar de destaque como sujeito de si e de suas escolhas.

As situações que emergem nos cenários das ruas são singulares dentro de um universo de demandas imprevisíveis e subjetivas, reforçando a imperiosa necessidade de compreender o cuidado numa perspectiva em que o profissional faça a distinção entre multi, inter e transdisciplinaridade, e receba dos gestores o suporte necessário para o desenvolvimento de ações transdisciplinares, em que se fazem necessárias as trocas de olhares repletos de especificidade.

Observou-se que entre os entrevistados apenas dois referiram experiência anterior em saúde mental. Essa leitura reflete a necessidade dos gestores em rever a formação das equipes, considerando que as suas atividades incluem a busca ativa e o cuidado integral aos usuários de substâncias psicoativas.

É importante ressaltar que a estratégia do Consultório de Rua ainda é incipiente e suas ferramentas de trabalho são pautadas nas políticas públicas, planejadas com o propósito de uma assistência integral à população. Conclui-se que é necessário ampliar a proposta dos Consultórios de Rua para atender à demanda de rua, bem como investir em recursos humanos especializados com formação em saúde mental e saúde coletiva, e ainda, na educação permanente em saúde, para atuar junto às pessoas de rua, intensificando o trabalho nas comunidades com os demais atores sociais. 


\section{Resumen}

Existen dos fenómenos distintos que están interconectados y son considerados graves problemas de salud pública: vivir en las calles y el consumo de drogas. Frente a estos problemas los equipos de salud callejera estaban favoreciendo un enfoque de salud aplicado a contextos de vida de gente sin hogar y drogodependientes. El objetivo fue conocer las prácticas de salud llevadas a cabo todos los días en los equipos de salud callejera, y describir sus estrategias de acción, puesto que el conocimiento sobre educación sanitaria es muy importante, así como revelar los sentimientos sobre la realización de este trabajo en la calle. Se trata de una investigación cualitativa, observación participativa y análisis de contenido propuesto por Bardin. Tras el análisis de las entrevistas a los 15 participantes, surgieron cinco temas. Para la mejora de los hábitos de salud en estos grupos poblacionales los equipos estaban a favor de la cercanía con los sin techo y la recepción a los mismos en las calles, lo que refuerza la importancia de la función del usuario y su conexión en una red interdisciplinaria e intersectorial.

Pesonas Sin Hogar; Consumidores de Drogas;

Educación em Salud; Salud Mental

\section{Colaboradores}

F. P. Silva participou da concepção, projeto, execução da pesquisa e redação do artigo. I. S. Frazão contribuiu na aprovação da versão final. F. M. P. Linhares colaborou na revisão crítica do texto.

\section{Agradecimentos}

Nossos agradecimentos aos gestores dos municípios que permitiram a nossa pesquisa e principalmente ao acolhimento que a pesquisadora responsável recebeu das equipes dos Consultórios de Rua.

\section{Referências}

1. Roseantock KIV, Neves MJ. Papel do enfermeiro da atenção básica de saúde na abordagem ao dependente de droga em João Pessoa, PB, Brasil. Rev Bras Enferm 2010; 63:581-6.

2. Prata EMM, Santos MA. O processo de saúde-doença e a dependência química: interfaces e evolução. Psicol Teor Prát 2009; 25:203-11.

3. Morais NA, Morais CA, Reis S, Koller SH. Promoção de saúde e adolescência: um exemplo de intervenção com adolescentes em situação de rua. Psicol Soc 2010; 22:507-18.

4. Alves VS. Modelos de atenção à saúde de usuários de álcool e outras drogas: discursos políticos, saberes e práticas. Cad Saúde Pública 2009; 25:2309-19.

5. Nery Filho A, Valério ALR, organizadores. Módulo de capacitação dos profissionais do Projeto Consultório de Rua. Brasília: Secretaria Nacional de Políticas sobre Drogas/Salvador: Centro de Estudos e Terapia de Abuso de Drogas; 2010.

6. Raup LM, Adorno RCF. Jovens em situação de rua e usos de crack: um estudo etnográfico em duas cidades. Revista Brasileira de Adolescência e Conflitualidade 2011; (4):52-67.
7. Wodak A. Harm reduction is now the mainstream global drug policy. Addiction 2009; 104:343-5.

8. Moreira FG, Neil M, Silveira DX. Drogas, família e adolescência. São Paulo: Editora Atheneu; 2009.

9. Aristides JL, Lima JVC. Processo saúde-doença da população em situação de rua da Cidade de Londrina: aspectos do viver e do adoecer. Espaç Saúde 2009; 10(2). http://www.ccs.uel.br/espacopara saude/v10n2/Artigo7.pdf.

10. Passos EH, Souza TP. Redução de danos e saúde pública: construção de alternativas à política global de "guerra às drogas". Psicol Soc 2011; 23:154-62.

11. Lima AF. Dependência de drogas e psicologia social: um estudo sobre o sentido das oficinas terapêuticas e o uso de drogas a partir da teoria de identidade. Psicol Soc 2008; 20:91-101.

12. Souza KM, Monteiro S. A abordagem da redução de danos em espaços educativos não formais: um estudo qualitativo no Estado do Rio de Janeiro. Interface Comun Saúde Educ 2011; 15:833-44.

13. Andrade T. Reflexões sobre políticas de drogas no Brasil. Ciênc Saúde Coletiva 2011; 16:4665-74. 
14. Secretaria de Atenção à Saúde, Ministério da Saúde. Consultório de Rua do SUS. Brasília: Ministério da Saúde; 2010.

15. Brasil. Portaria no 122 , de 25 de janeiro de 2012 : define as diretrizes e funcionamento das equipes de Consultório de Rua. Diário Oficial da União 2012; 26 jan.

16. Liberalesso RCB. Educação social de rua e os pressupostos educacionais freireanos. Educere et Educare - Revista de Educação UFSM/RS 2008 3:117-23.

17. Freire P. Pedagogia do oprimido. 46a Ed. São Paulo: Editora Paz \& Terra; 2007.

18. Minayo MCS. O desafio do conhecimento: pesquisa qualitativa em saúde. 8a Ed. São Paulo: Editora Hucitec/Rio de Janeiro: ABRASCO; 2004.

19. Secretaria de Estado e Saúde de Santa Catarina. ABC: redução de danos. Florianópolis: Secretaria de Estado e Saúde de Santa Catarina; 2009.

20. Polit DR, Beck CT. Fundamentos de pesquisa em enfermagem: métodos, avaliação e utilização. 7a Ed. Porto Alegre: Editora Artmed; 2011.

21. Bardin L. Análise conteúdo. 5ạ Ed. Lisboa: Edições 70; 2010.

22. Freire P. Pedagogia da autonomia: saberes necessários à prática educativa. 29ạ Ed. São Paulo: Editora Paz \& Terra; 1996.
23. Freire P. Conscientização: teoria e prática da libertação. 3a Ed. São Paulo: Centauro; 2006.

24. Ministério da Saúde. Abordagens terapêuticas a usuários de cocaína/crack no Sistema Único de Saúde. Brasília: Ministério da Saúde; 2010.

25. Ministério da Saúde. Relatório final da IV Conferência Nacional de Saúde Mental-Intersetorial. Brasília: Ministério da Saúde; 2011.

26. Botti NCL, Castro CC, Silva MF, Silva AK, Oliveira LC, Castro ACHOA, et al. Prevalência de depressão entre homens adultos em situação de rua em Belo Horizonte. J Bras Psiquiatr 2010; 59:10-6.

27. Freire P. Educação e mudança. 29ạ Ed. São Paulo: Editora Paz \& Terra; 2002.

28. Severo SB, Seminotti N. Integralidade e transdisciplinaridade em equipes multiprofissionais na saúde coletiva. Ciênc Saúde Coletiva 2010; 15 Suppl 1:1695-8.

29. Vargas D, Duarte FAB. Enfermeiros dos centros de atenção psicossocial em álcool e drogas (CAPS ad); a formação e a busca pelo conhecimento específico da área. Texto \& Contexto Enferm 2011; 20:119-26.

Recebido em 16/Mai/2013

Versão final reapresentada em 05/Set/2013

Aprovado em 04/Out/2013 